\title{
Patient-Reported Outcome Measures in Pancreatic Cancer Receiving Radiotherapy
}

\author{
Ramez Kouzy ${ }^{1,2,+} \mathbb{C}$, Joseph Abi Jaoude ${ }^{1,2,+} \mathbb{C}$, Daniel Lin ${ }^{1,2}$, Nicholas D. Nguyen ${ }^{1,2} \mathbb{D}$, \\ Molly B. El Alam ${ }^{1,2}$, Ethan B. Ludmir ${ }^{1}(\mathbb{D}$ and Cullen M. Taniguchi $1,2, * \mathbb{D}$ \\ 1 Department of Radiation Oncology, MD Anderson Cancer Center, Houston, TX 77030, USA; \\ rkouzy@mdanderson.org (R.K.); Jbabi@mdanderson.org (J.A.J.); dlin4@mdanderson.org (D.L.); \\ NDNguyen1@mdanderson.org (N.D.N.); mbel@mdanderson.org (M.B.E.A.); \\ ebludmir@mdanderson.org (E.B.L.) \\ 2 Department of Experimental Radiation Oncology, MD Anderson Cancer Center, Houston, TX 77030, USA \\ * Correspondence: Ctaniguchi@mdanderson.org \\ + These authors contributed equally as first authors.
}

Received: 22 May 2020; Accepted: 28 August 2020; Published: 2 September 2020

check for updates

Simple Summary: Cancer therapies should improve patient survival or at least improve the quality of their life as they receive treatment for their disease. This is particularly important in pancreatic cancer, where current treatments often have to balance between limiting tumor growth and minimizing patient toxicity. There has been an increasing appreciation among physicians to capture the patient's voice using tools called patient-reported outcome measures (PROM). In this article, we describe the available PROMs and their relative strengths and weaknesses to help oncologists make sense of this rapidly growing field. Finally, we present a decision-making tool that can help researchers and clinicians select the ideal PROM that fits their needs.

Abstract: Pancreatic cancer and its treatment often dramatically impact patients' quality of life (QoL). Given this, as well as increased focus on QoL measures in clinical oncology, there has been a rise in the number of instruments that measure patient-reported outcomes (PROs). In this review, we describe the landscape of different PRO instruments pertaining to pancreatic cancer, with specific emphasis on PRO findings related to pancreatic cancer patients receiving radiotherapy (RT). Twenty-five of the most commonly utilized PROs are compared in detail. Notably, most of the PRO tools discussed are not specific to pancreatic cancer but are generic and have been used in various malignancies. Published findings concerning PROs in pancreatic cancer involving RT are also extracted and summarized. Among the measures used, the European Organization for Research and Treatment Cancer QLQ-C30 was the most commonly utilized. We recommend a careful selection of PRO measures in clinical pancreatic cancer research and care and encourage the use of a combination of symptom-specific and global QoL tools to more fully capture patients' perspectives.

Keywords: patient reported outcomes; quality of life; pancreatic cancer; radiotherapy

\section{Introduction}

Patient-reported outcomes (PROs) are measures directly obtained from patients, including but not limited to emotional well-being, general quality of life (QoL), and physical and psychological symptoms. Since their introduction in the late 1960s, PROs have gained more attention over the 30 years that followed. The utility of PROs is now widely acknowledged both in clinical practice and research. This trend is particularly striking in clinical oncology, where there are widespread efforts dedicated to improving value-based quality of life for cancer patients. Professional organizations like 
the American Society of Clinical Oncology (ASCO) and the European Society of Medical Oncology (ESMO) now recommend the inclusion of PROs as central endpoints in modern clinical trials $[1,2]$. These guidelines are driven, in part, by the importance of QoL endpoints as real meaningful target goals and by studies having demonstrated better survival when PROs were collected, potentially due to earlier interventions preventing downstream consequences [3,4]. Furthermore, the Food and Drug Administration (FDA) has been increasingly shedding light on the value and use of PRO data in labeling and regulations. This enables quality-of-life metrics to be taken into consideration for drug approvals, in addition to quantity-of-life metrics such as overall survival (OS) or disease-control-related surrogates, most notably progression-free survival (PFS) [5-7].

In oncology, clinicians often assess toxicity and adverse events (AE) using standardized lexicons, such as the Common Terminology Criteria for Adverse Events (CTCAE). While historically adopted and extensively used, CTCAE toxicity measures rely primarily on physician or provider-based assessments of patients' health and well-being. Such assessments are useful and often essential in order to properly assess and follow-up on patients. However, numerous studies show that CTCAE results and PRO results are not always congruent $[8,9]$. Contrary to the CTCAE, PRO data rely solely on the patient's report. When studied further, data show that PROs capture the patient perspective in a complimentary manner to the clinician-based CTCAE report [8]. To illustrate this relationship, the National Cancer Institute (NCI) developed the patient-reported outcomes version of the CTCAE (PRO-CTCAE) to complement the clinician-reported CTCAE and aid in systematically capturing a wide spectrum of adverse events [10]. In light of proven differences between patient- and physician-based adverse events grading, experts call for the incorporation of both CTCAE and PRO in cancer clinical trials, in order to enhance the accuracy of adverse event reporting.

The standard methodology of acquiring patient-reported outcomes is through a questionnaire answered directly by the patient. The tools or instruments used to collect PROs are referred to as patient-reported outcome measures (PROMs). The precise methodology behind the development of PROMs varies. Generally, PROMs are designed based on adverse events that could be appropriate for patients to self-report. Those PROMs test specific domains and are typically developed with input from a variety of multidisciplinary stakeholders, including patients, clinicians, and psychometricians (for proper psychological measurements). In PROMs, a domain is made out of a number of measurable items that collectively describe a specific function or perception.

Each PROM must be validated in a specific patient population and should be capable of capturing the clinical differences effectively. These tools can either be general or disease-specific. Generic scales have the capability to measure a variety of different outcomes without venturing into a specific disease or outcome, like general physical function, pain, or social function. Disease-specific scales are usually tailored to a particular disease or set of diseases; they have the capability to shed focused attention on specific issues that are relevant to a particular disease process and/or its associated treatment. For instance, patients undergoing radiation therapy for pancreatic cancer may experience gastrointestinal toxicities secondary to radiation fields targeting the abdominal area, with a predominance of symptoms related to bowel dysfunction and toxicity. In such cases, PROMs measuring salivary gland function or respiratory symptoms may yield less useful information. Fortunately, many instruments are readily available now and can allow a researcher to easily capture the PROs for any specific disease site. The use of such PROMs has the potential to improve symptom reporting and management, as well as the establishment of an environment of understanding between patients and physicians. PROs offer the treating physician the opportunity to gain insight into the patient's experiences while complementing the clinician's assessment [11].

Understanding the patient experience is critical in the treatment of pancreatic cancer, since patients tend to experience substantial disease-related morbidity compounded by treatment-related toxicity from therapies such as RT; major surgeries (e.g., Whipple procedures); and potent multi-agent chemotherapies such as FOLFIRINOX (leucovorin, fluorouracil, irinotecan, and oxaliplatin) [12,13]. Despite the numerous modern clinical trials in pancreatic cancer, prognosis remains poor, with five-year 
survival rates of less than $10 \%$. The poor clinical outcomes of patients with pancreatic cancer are not projected to improve in the near future, despite an ongoing rise in cancer incidences [14]. Therefore, it is crucial to design adequate quality-of-life tools in this population, since quantity of life remains unacceptably low [15]. Unfortunately, there is a substantial knowledge gap in PROs for the various available treatments of pancreatic cancer, particularly radiotherapy. This partly stems from a rapidly growing body of knowledge concerning the availability of PROMs and a lack of standardization across the field, as well as an increased emergence of novel RT technologies for the treatment of pancreatic cancer-in particular, stereotactic body RT (SBRT). In this review, we identify and summarize the different PRO instruments currently available for use in clinical and research settings and highlight $\mathrm{PRO}$ results from pivotal radiation studies in pancreatic cancer. We suggest potentially promising PRO metrics for clinical trials involving emerging therapies, such as SBRT.

\section{Patient-Reported Outcome Measures in Pancreatic Cancer}

Many PROMs have been studied in pancreatic cancer patients. Each tool was adopted for a specific trial or a subpopulation of patients with this disease. This has led to the creation of multiple excellent PROMs with their own unique scope, domain, and psychometric properties. However, this creates a problem for a trialist or researcher who wishes to implement a PRO metric into their own study—how do you select the right one?

The ideal PROM is brief but able to capture the symptomatology relevant to the disease of interest. Table 1 offers an overview of the available PROMs that have been utilized in pancreatic cancer. Generic PRO instruments cover a wide range of symptomatology without focusing on a particular domain or scope. Among the generic PROMs used in pancreatic cancer are the Short Form 36 (SF-36), the Brief Pain Inventory (BPI), and the Spitzer Quality of Life (QLI) tools. The SF-36 and its shorter version, the SF-12, remain widely used and are easy to both implement and interpret. Other PRO measures like the European Organization for Research and Treatment of Cancer Quality of Life Questionnaire Core 30 (EORTC-QLQ-C30), the Functional Assessment of Cancer Therapy-General (FACT-G), the MD Anderson Symptom Inventory (MDASI), and the EuroQoL 5Q cover broad areas like functional, physical, emotional, social, and cognitive domains. As such, these scales have been widely used, validated, and translated into various languages; however, they may not all be relevant across contexts and patient populations in oncology [16].

The use of cancer-specific measures like the EORTC or FACT-G, however, are thought to better capture the symptoms of oncological diseases and their treatments [17]. Both EORTC and FACT-G have great utility in cancer studies, since they can be broken into symptoms that focus on a particular cancer or group of malignancies, such as the EORTC-PAN26 and Pancreatic Cancer Disease Impact (PACADI) for pancreatic cancer. Of note, the EORTC-PAN26 has been found to be conceptually relevant to pancreatic cancer patients and tends to cover all concerns that the patients may experience, except neuropathic pain [18]. 
Table 1. Patient-reported outcome (PRO) instruments available for use in pancreatic cancer.

\begin{tabular}{|c|c|c|c|c|c|}
\hline Instrument & Items & $\begin{array}{l}\text { Average Time } \\
\text { Needed }\end{array}$ & Population for Intended Use & Scope & Recall Period \\
\hline BFI [19] & 4 items & $5 \mathrm{~min}$ & $\begin{array}{c}\text { Cancer patients regardless of } \\
\text { treatment status }\end{array}$ & $\begin{array}{c}\text { Impact and severity of cancer-related } \\
\text { fatigue }\end{array}$ & $24 \mathrm{~h}$ \\
\hline $\begin{array}{l}\text { BPI [20] * } \\
\text { BPI short form }\end{array}$ & $\begin{array}{l}32 \text { items } \\
9 \text { items }\end{array}$ & $\begin{array}{l}10 \mathrm{~min} \\
5 \mathrm{~min}\end{array}$ & $\begin{array}{l}\text { Patients with chronic or acute } \\
\text { pain }\end{array}$ & $\begin{array}{l}\text { Severity and impact on daily } \\
\text { functions of cancer-related pain }\end{array}$ & $24 \mathrm{~h} / 1$ week \\
\hline CARES [21] & 59 items & $30 \mathrm{~min}$ & $\begin{array}{l}\text { Cancer patients regardless of } \\
\text { treatment status }\end{array}$ & $\begin{array}{l}\text { Functional, physical, emotional, } \\
\text { social, and cognitive }\end{array}$ & 1 month \\
\hline Distress Thermometer [22] & $\begin{array}{l}1 \text { visual item } \\
35 \text { item problem list }\end{array}$ & $\begin{array}{l}1 \mathrm{~min} \\
3 \mathrm{~min}\end{array}$ & $\begin{array}{c}\text { Cancer patients regardless of } \\
\text { treatment status }\end{array}$ & $\begin{array}{c}\text { Distress level } \\
\text { Psychosocial and physical needs }\end{array}$ & 1 week \\
\hline $\begin{array}{l}\text { Edmonton Symptom } \\
\text { Assessment Scale [23] }\end{array}$ & 9 items & $5 \mathrm{~min}$ & $\begin{array}{c}\text { Cancer patients regardless of } \\
\text { treatment status }\end{array}$ & Psychosocial and physical needs & $\begin{array}{l}\text { Dependent on clinical } \\
\text { setting }\end{array}$ \\
\hline EORTC-QLQ-C30 [24] & 30 items & $10-15 \mathrm{~min}$ & $\begin{array}{c}\text { Cancer patients regardless of } \\
\text { treatment status }\end{array}$ & $\begin{array}{l}\text { Functional, physical, emotional, } \\
\text { social, and cognitive }\end{array}$ & 1 week \\
\hline EORTC-QLQ-C15-PAL [25] & 15 items & $5-10 \mathrm{~min}$ & $\begin{array}{l}\text { Cancer patients in palliative } \\
\text { care }\end{array}$ & $\begin{array}{l}\text { Functional, physical, emotional, } \\
\text { social, and cognitive }\end{array}$ & 1 week \\
\hline EORTC-QLQ-PAN26 [26] * & 26 items & $10-15 \mathrm{~min}$ & Pancreatic cancer patients & $\begin{array}{l}\text { Functional, physical, emotional, } \\
\text { social, and cognitive }\end{array}$ & 1 week \\
\hline EuroQoL (5Q-5D-5L) [27] & 5 items 1 visual scale & $5 \mathrm{~min}$ & $\begin{array}{c}\text { Cancer patients regardless of } \\
\text { treatment status }\end{array}$ & $\begin{array}{l}\text { Mobility, basic self-care, daily } \\
\text { activities, and pain, discomfort }\end{array}$ & 1 week \\
\hline FACIT-F [28] & 13 items & $5-10 \mathrm{~min}$ & Patients with chronic fatigue & $\begin{array}{c}\text { Impact and severity of cancer-related } \\
\text { fatigue }\end{array}$ & 1 week \\
\hline FACT-Hep [29] * & 45 items & $10-15 \mathrm{~min}$ & $\begin{array}{l}\text { Pancreatic and hepatobiliary } \\
\text { cancer patients }\end{array}$ & $\begin{array}{l}\text { Functional, physical, emotional, } \\
\text { social, and cognitive }\end{array}$ & 1 week \\
\hline FHSI-8 [30] * & 8 items & $5-10 \mathrm{~min}$ & $\begin{array}{l}\text { Pancreatic and hepatobiliary } \\
\text { cancer patients }\end{array}$ & $\begin{array}{l}\text { Functional, physical, emotional, } \\
\text { social, and cognitive }\end{array}$ & 1 week \\
\hline FHSI-18 [31] * & 18 items & $5-10 \mathrm{~min}$ & $\begin{array}{l}\text { Pancreatic and hepatobiliary } \\
\text { cancer patients }\end{array}$ & $\begin{array}{c}\text { Functional, physical, emotional, } \\
\text { social, and cognitive }\end{array}$ & 1 week \\
\hline GIQLI [32] * & 36 items & $10-15 \mathrm{~min}$ & $\begin{array}{c}\text { Patients with gastrointestinal } \\
\text { diseases }\end{array}$ & $\begin{array}{l}\text { GI symptoms, functional, physical } \\
\text { function, social, and emotional }\end{array}$ & 2 weeks \\
\hline MQOL [33] * & 17 items & $10-30 \mathrm{~min}$ & $\begin{array}{c}\text { Cancer patients regardless of } \\
\text { treatment status }\end{array}$ & $\begin{array}{l}\text { Functional, physical, emotional, } \\
\text { social, and cognitive }\end{array}$ & $48 \mathrm{~h}$ \\
\hline
\end{tabular}


Table 1. Cont.

\begin{tabular}{|c|c|c|c|c|c|}
\hline Instrument & Items & $\begin{array}{l}\text { Average Time } \\
\text { Needed }\end{array}$ & Population for Intended Use & Scope & Recall Period \\
\hline MDASI [34] * & 13 items & $6 \mathrm{~min}$ & $\begin{array}{c}\text { Cancer patients regardless of } \\
\text { treatment status }\end{array}$ & $\begin{array}{l}\text { Psychological and physical } \\
\text { symptoms }\end{array}$ & $24 \mathrm{~h}$ \\
\hline MDASI-GI [35] * & 24 items & $5 \mathrm{~min}$ & $\begin{array}{l}\text { Cancer patients with symptoms } \\
\text { caused by gastrointestinal } \\
\text { cancer and its treatment }\end{array}$ & $\begin{array}{l}\text { Functional, psychological, and } \\
\text { gastrointestinal physical symptoms }\end{array}$ & $24 \mathrm{~h}$ \\
\hline MSAS [36] * & 32 items & $15 \mathrm{~min}$ & $\begin{array}{c}\text { Cancer patients regardless of } \\
\text { treatment status }\end{array}$ & $\begin{array}{l}\text { Psychological and physical } \\
\text { symptoms }\end{array}$ & 1 week \\
\hline PACADI [37] * & 8 items & $<5 \min$ & Pancreatic cancer patients & $\begin{array}{l}\text { Psychosocial and physical needs } \\
78 \text { symptoms from treatment }\end{array}$ & 1 week \\
\hline PRO-CTCAE [38] & 124 items & 20 items $3.4 \mathrm{~min}$ & Cancer patients in clinical trials & $\begin{array}{l}\text { toxicities that can be selected to build } \\
\text { custom forms }\end{array}$ & 1 week \\
\hline PROMIS [39] & $4-8$ items per symptom & $5 \mathrm{~min}$ & People with health conditions & $\begin{array}{l}\text { Global health, distress, physical } \\
\text { symptoms, cognitive function, etc. }\end{array}$ & 1 week \\
\hline $\begin{array}{l}\text { SF-36 [40] } \\
\text { SF-12 [41] }\end{array}$ & $\begin{array}{l}36 \text { items } \\
12 \text { items }\end{array}$ & $\begin{array}{l}10-15 \min \\
2-3 \min \end{array}$ & People with health conditions & $\begin{array}{l}\text { Global health, distress, physical } \\
\text { symptoms, cognitive function, etc. }\end{array}$ & 1 month/1 week \\
\hline $\begin{array}{l}\text { Spitzer Quality of Life (QLI) } \\
{[42]}\end{array}$ & 5 items & $1 \mathrm{~min}$ & Terminally ill patients & $\begin{array}{l}\text { Daily activity, perceptions, behavior, } \\
\text { and support }\end{array}$ & 1 week \\
\hline
\end{tabular}

* = Validated in the pancreatic cancer population, BFI = Brief Fatigue Inventory, BPI = Brief Pain Inventory, CARES = Cancer Rehabilitation Evaluation System, EORTC-QLQC30 = European

Organization for Research and Treatment of Cancer Quality of Life Questionnaire Core 30, EORTC-QLQ-C15-PAL = European Organization for Research and Treatment of Cancer Quality of Life Questionnaire for Palliative Care, EORTC-QLQ-PAN26 = European Organization for Research and Treatment of Cancer Quality of Life Questionnaire for Pancreatic Cancer, FACIT-F = Functional Assessment of Chronic Illness Therapy-Fatigue, FACT-Hep = Functional Assessment of Cancer Therapy-Hepatobiliary Cancer, FHSI = Functional Assessment of Cancer Therapy-Hepatobiliary Symptom Index, GIQLI = Gastrointestinal Quality of Life Index, MQOL = McGill Quality of Life, MDASI = MD Anderson Symptom Inventory, MDASI-GI = MD Anderson Symptom Inventory for gastrointestinal cancer, MSAS = Memorial System Assessment Scale, PACADI = Pancreatic Cancer Disease Impact, PRO-CTCAE = Patient-Reported Outcomes version of the Common Terminology Criteria for Adverse Events, PROMIS = Patient-Reported Outcomes Measurement Information System, and SF-36 = Short Form Health Survey. 
The importance of the patient perspective is growing in clinical trial design and endpoint selection. To that end, the FDA has established a list of core concepts regarding what a PRO measure(s) should assess [43], which includes symptoms related to disease and treatment, practical physical abilities, and standard adverse event reporting. PRO data generated from clinical trials help to define tolerability, safety, and the overall patient benefit of any intervention. Furthermore, the FDA now allows pharmaceutical companies to submit PRO data as a supplement for regulatory and labeling decisions, which can help approve novel medications that offer benefits in terms of quality of life and outcomes. As evidenced by Table 1, there exist a multitude of domains that cover cancer symptomatology but only a handful that are related to upper abdominal malignancies like pancreatic cancer. Identifying the PROM that captures the outcomes of interest is of paramount importance. Investigators and clinicians need to determine whether the measurement they are choosing adequately reflects their concept of interest.

In Figure 1, we offer a simplified algorithm that can help pancreatic cancer researchers and trialists in selecting PROMs based on the research question they are interested in answering. After surveying and consulting with stakeholders on the endpoints of interest, researchers should locate and select a relevant PROM. For example, a researcher or clinician studying the side effects of a pancreatic cancer therapy might want to measure gastrointestinal symptoms, as well as general well-being. They would then locate a PROM that would measure both, such as the MDASI-GI. After locating a tool, the clinician/researcher would comb the literature to study if the PROM is valid and reliable in the population and setting of interest. The researcher would then go on to check each box in Figure 1; if the answer is satisfactory, they would move along the algorithm. If, on the other hand, the located PROM does not comply with any of the steps along the algorithm, the researcher/clinician would have to locate another tool and start the process again. 


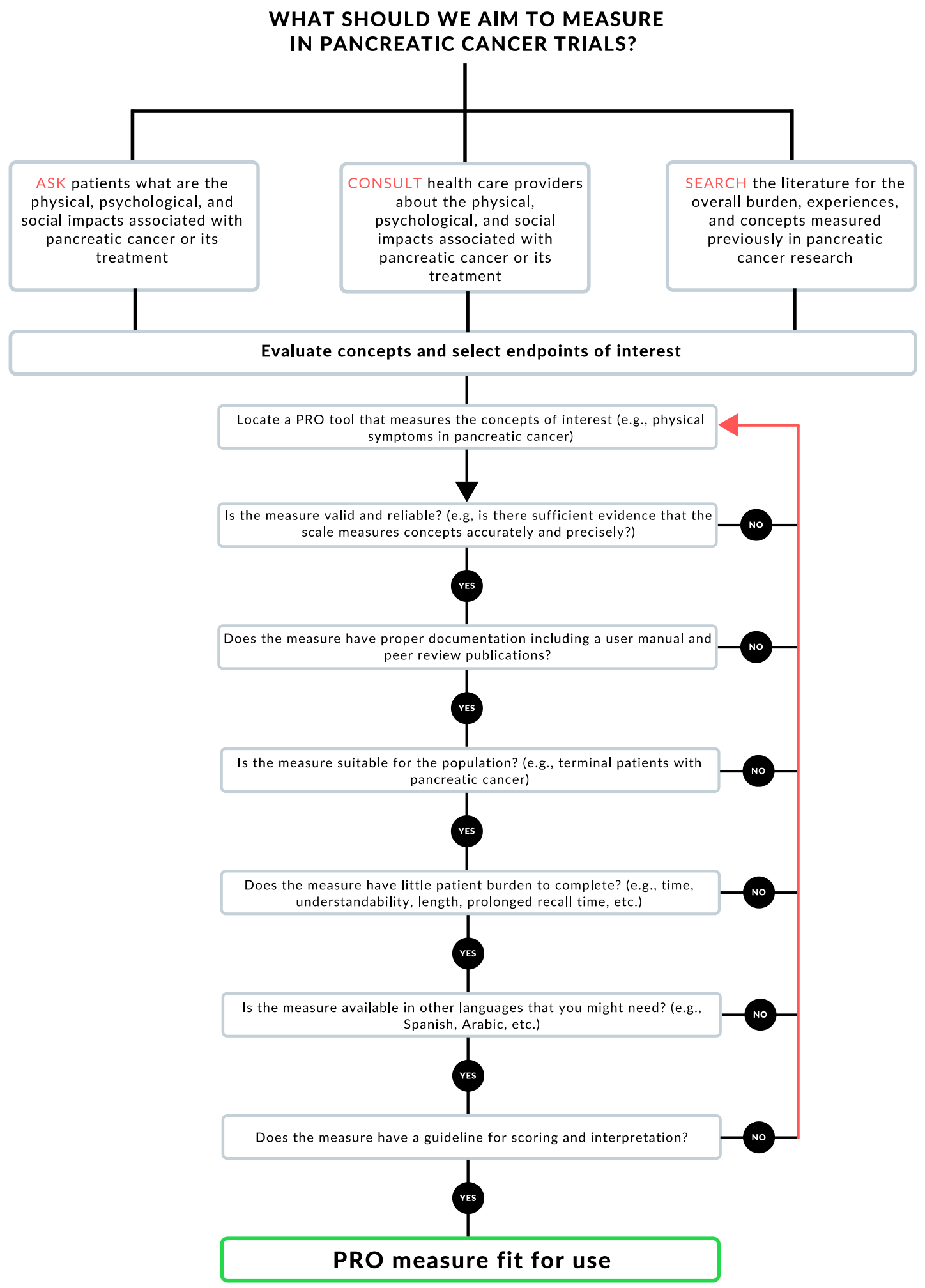

Figure 1. Patient-reported outcome (PRO) measure selection algorithm.

\section{PRO Measures in Pancreatic Cancer Studies Using Radiotherapy}

Surgery is the only known way to cure pancreatic cancer, and there have been several studies examining patient experiences with the Whipple procedure. Since surgery is not possible in most forms of pancreatic cancer (nearly $85 \%$ of patients, including patients with metastatic or locally advanced disease), RT is the only tested option to achieve local control. Definitive chemoradiation to pancreatic 
cancer is challenging because these tumors often grow into and around the nearby gastrointestinal tract, which cannot tolerate high doses of radiation. A highly conformal technique called stereotactic body radiation therapy (SBRT) delivers focused doses of radiation to the tumor, which results in better control with less injury to highly susceptible organs near the pancreas. Early SBRT studies for pancreatic cancer yielded unacceptable toxicity, but subsequent refinement of the technique has SBRT greatly improved and better local control and QoL [44-48] compared to conventional RT. Some studies suggest that this approach may synergize with immunotherapy or be dose-escalated with intensity-modulated radiation therapy (IMRT) or carbon ions.

The potential promise of radiation therapy in pancreatic cancer has been met with concerns over side effects and QoL, which has led investigators and clinicians to incorporate PRO measures in trials where radiation therapy was used. Table 2 highlights pancreatic cancer studies where QoL data were measured for radiation therapy and great heterogeneity of PRO data. In general, the use of RT pointed to a trend of better QoL without excessive toxicity, but an overarching conclusion cannot yet be reached, because PROs were not uniformly applied. The PROMs used in these pancreatic cancer studies with radiation varied widely from generic tools like the SF-36 to pancreatic cancer-specific tools such as the EORTC-QLQ-PAN26. In reporting the results of a phase 2 trial of SBRT for pancreatic cancer patients, Herman et al. utilized the EORTC-QLQ-C30/PAN26 to demonstrate that the addition of SBRT did not change patients' global QoL (possibly a reflection of limited/minimal toxicities from SBRT) while improving patients' pain (likely a reduction in tumor-related pain) [49]. This further highlights the importance of PRO measure selection in the study design and its ability to capture the intended changes in this specific population.

EORTC-QLQ-C30/PAN26 and FACT-Hep were the two most commonly used tools among pancreatic cancer trials [18] (Figure 1). These two PROMs are likely to be useful across a spectrum of pancreatic cancer trial designs, since these tools measure concepts of interests-in this case, cancer-specific symptomatology linked directly to pancreatic cancer. These tools have been validated and shown to be reliable, with a body of literature supporting their utilization. Additionally, both tools are accompanied by documents dictating the best practices, dealing with missing data, and analyses. The EORTC-QLQ-C30/PAN26 and FACT-Hep are validated and reliable in the pancreatic cancer population, with a similar time burden of 10-15 min (Table 1), which is reasonable. Additionally, both tools have a recall period of one week, which captures changes early enough while not burdening the patients with such a long recall period that they might cause undue difficulty recalling symptoms effectively. Moreover, both tools are available in multiple languages, which increases access to patients. Finally, these PROMs are supported by manuals for scoring and interpretation that can be found on their corresponding websites. In summary, these tools are tailored and fit for measuring PROs in pancreatic cancer trials and should be recommended for future utilization. 
Table 2. PRO in studies of pancreatic cancer involving radiation therapy.

\begin{tabular}{|c|c|c|c|}
\hline Author & Study Aim & PRO Measure & Outcome \\
\hline Polistina et al. [50] & $\begin{array}{l}\text { Assessment of treatment response, local control, } \\
\text { downstaging, pain, and QoL in patients with } \\
\text { unresectable locally advanced PDAC undergoing SBRT. }\end{array}$ & SF-36 & $\begin{array}{l}\text { No QoL difference between pretreatment vs. 3- or } \\
\text { 6-month control follow-ups. }\end{array}$ \\
\hline Quan et al. [51] & $\begin{array}{l}\text { Phase } 2 \text { clinical trial evaluating efficacy and safety of } \\
\text { induction chemotherapy, followed by stereotactic } \\
\text { ablative radiation therapy in borderline resectable and } \\
\text { locally advanced PDAC. }\end{array}$ & FACT-G & $\begin{array}{l}\text { No QoL difference between pretreatment and post } \\
\text { chemotherapy, SABR, or surgery. }\end{array}$ \\
\hline Krempien et al. [52] & $\begin{array}{l}\text { Phase } 2 \text { clinical trial evaluating Cetuximab and } \\
\text { chemoradiation (IMRT) in locally advanced PDAC. }\end{array}$ & EORTC QLQ-C30, EORTC QLQ-PAN26 & Not available. \\
\hline Morak et al. [53] & $\begin{array}{l}\text { Comparison between QoL in patients who underwent } \\
\text { adjuvant CRT compared to those who did not. }\end{array}$ & EORTC QLQ-C30 & $\begin{array}{l}\text { Better QoL in patients who underwent neoadjuvant } \\
\text { CRT vs. observation only. }\end{array}$ \\
\hline Knaebel et al. [54] & $\begin{array}{l}\text { Comparison between OS between adjuvant } \\
\text { 5-fluorouracil, cisplatin, interferon alpha, and radiation } \\
\text { therapy vs. folinic acid and 5-fluorouracil. }\end{array}$ & $\begin{array}{c}\text { EORTC QLQ-C30, EORTC QLQ-PAN26, } \\
\text { CES-D }\end{array}$ & Not available. \\
\hline Herman et al. [49] & $\begin{array}{l}\text { Phase } 2 \text { clinical trial evaluating gemcitabine and SBRT } \\
\text { in patients with locally advanced unresectable PDAC. }\end{array}$ & EORTC QLQ-C30, EORTC QLQ-PAN26 & $\begin{array}{l}\text { Global QoL scores remained stable from baseline to } \\
\text { after SBRT. Pain scores improved } 4 \text { weeks after } \\
\text { SBRT. }\end{array}$ \\
\hline Serrano et al. [55] & $\begin{array}{l}\text { To determine QoL during and after neoadjuvant CRT } \\
\text { and surgery for patients with PDAC. }\end{array}$ & $\begin{array}{c}\text { EORTC QLQ-C30, EORTC QLQ-PAN26, } \\
\text { FACT-Hep }\end{array}$ & $\begin{array}{l}\text { After neoadjuvant CRT, a transient increase in GI } \\
\text { symptoms and a decrease in physical functioning } \\
\text { were seen. After surgical resection, most QoL } \\
\text { domains returned to baseline. }\end{array}$ \\
\hline Short et al. [56] & $\begin{array}{l}\text { To determine QoL as part of a phase } 2 \text { trial using the 3D } \\
\text { conformal CRT sandwich technique in PDAC. }\end{array}$ & EORTC QLQ-C30, EORTC QLQ-PAN26 & $\begin{array}{c}\text { CRT improved local symptoms while not worsening } \\
\text { global QoL. }\end{array}$ \\
\hline Katz et al. [57] & $\begin{array}{l}\text { To compare the efficacy of preoperative 5-FU vs. 5-FU } \\
\text { plus hypofractionated SBRT/HIGRT in borderline } \\
\text { resectable PDAC, primarily focused on evaluating and } \\
\text { estimating the } 18 \text {-month OS rate. }\end{array}$ & PRO-CTCAE & Not available. \\
\hline Haddock et al. [58] & $\begin{array}{l}\text { Phase } 2 \text { clinical trial to determine the efficacy, toxicity, } \\
\text { and effects on QoL of radiotherapy with gemcitabine } \\
\text { and cisplatin for patients with locally advanced PDAC. }\end{array}$ & $\begin{array}{l}\text { SDS } \\
\text { LASA }\end{array}$ & $\begin{array}{l}\text { No significant overall QoL difference between } \\
\text { baseline and the last measurement. However, } \\
\text { overall SDS scores indicated improved QoL } \\
\text { (specifically insomnia, frequency of pain, and } \\
\text { outlook). LASA pain scores improved. }\end{array}$ \\
\hline
\end{tabular}


Table 2. Cont

\begin{tabular}{|c|c|c|c|}
\hline Author & Study Aim & PRO Measure & Outcome \\
\hline Heras et al. [59] & $\begin{array}{l}\text { To analyze the effect of RT with 5-FU vs. RT with } \\
\text { gemcitabine on QoL in patients with unresectable } \\
\text { pancreatic cancer. }\end{array}$ & EORTC QLQ-C30 & $\begin{array}{l}\text { Overall QoL for both arms with RT significantly } \\
\text { improved notably for cognitive function, decreased } \\
\text { fatigue, and reduced appetite loss. }\end{array}$ \\
\hline Hurt et al. [60] & $\begin{array}{l}\text { To report QoL in patients with locally advanced } \\
\text { pancreatic cancer during and after treatment with Cap- } \\
\text { or Gem-CRT. }\end{array}$ & EORTC QLQ-C30, EORTC QLQ-PAN26 & $\begin{array}{c}\text { QoL improved at the induction of CRT, experienced } \\
\text { significant decline during CRT, and recovered after } \\
\text { the end of CRT in patients. Slight QoL differences } \\
\text { favoring Cap-CRT. }\end{array}$ \\
\hline Loehrer Sr et al. [61] & $\begin{array}{l}\text { To evaluate Gem-CRT vs. Gem alone in patients with } \\
\text { localized unresectable pancreatic cancer to determine if } \\
\text { radiation improves survival or provides additional QoL. }\end{array}$ & FACT-Нер & $\begin{array}{l}\text { No statistically significant QoL differences between } \\
\text { Gem-CRT vs. Gem alone from the baseline } \\
\text { comparison beyond week } 6 \text {. However, there was a } \\
\text { statistically significant decline in QoL among } \\
\text { participants within each treatment arm from } \\
\text { baseline to week } 6 .\end{array}$ \\
\hline Moore et al. [62] & $\begin{array}{l}\text { Phase III trial to evaluate the effects of the addition of } \\
\text { Erlotinib with Gemcitabine in patients with } \\
\text { unresectable, locally advanced, or metastatic pancreatic } \\
\text { cancer. }\end{array}$ & EORTC QLQ-C30 & $\begin{array}{l}\text { No significant difference in QoL between both } \\
\text { treatment groups, with the exception of worsening } \\
\text { diarrhea in the Erlotinib + Gemcitabine group. }\end{array}$ \\
\hline Neoptolemos et al. [63] & $\begin{array}{l}\text { Randomized control trial to evaluate the role of } \\
\text { adjuvant chemoradiation and chemotherapy in patients } \\
\text { with resectable pancreatic cancer. }\end{array}$ & $\begin{array}{l}\text { ESPAC-1 QoL Form (based on EORTC } \\
\text { QLQ-C30) }\end{array}$ & $\begin{array}{l}\text { Overall, QoL increased for treatment groups } \\
\text { (adjuvant CRT and chemotherapy vs. null) over } \\
3 \text { months from the baseline. }\end{array}$ \\
\hline Neoptolemos et al. [64] & $\begin{array}{l}\text { Phase } 3 \text { trial to evaluate the efficacy and safety of the } \\
\text { combination of gemcitabine and capecitabine vs. } \\
\text { gemcitabine alone in patients with resected pancreatic } \\
\text { cancer. }\end{array}$ & EORTC QLQ-C30 & $\begin{array}{l}\text { No significant effect in the longitudinal estimate of } \\
\text { QoL by treatment group. }\end{array}$ \\
\hline Oettle et al. [65] & $\begin{array}{l}\text { To determine whether adjuvant gemcitabine } \\
\text { post-resection of pancreatic cancer improves } \\
\text { disease-free survival by } 6 \text { months or more. }\end{array}$ & Spitzer QL-Index & $\begin{array}{l}\text { QoL improved in both groups, with no significant } \\
\text { differences between groups at any time point. }\end{array}$ \\
\hline Conroy et al. [66] & $\begin{array}{l}\text { Phase } 2 \text { and } 3 \text { trials to explore the differences between } \\
5 \text {-FU and single-agent gemcitabine as a first-line } \\
\text { treatment in patients with metastatic pancreatic cancer. }\end{array}$ & EORTC QLQ-C30 & $\begin{array}{l}\text { No overall differences in QoL between treatment } \\
\text { groups, except 5-FU initially had higher scores for } \\
\text { diarrhea, or of QoL in the 5-FU group as compared } \\
\text { with the gemcitabine group. }\end{array}$ \\
\hline \multicolumn{4}{|c|}{$\begin{array}{l}\text { PDAC = Pancreatic ductal adenocarcinoma, SBRT = Stereotactic body radiation therapy, SF-36 = Short Form Health Survey, QoL = Quality of life, FACT-G = Functional Assessment of } \\
\text { Cancer Therapy - General, SABR = stereotactic ablative body radiotherapy, IMRT = Intensity modulated radiation therapy, EORTC-QLQC30 = European Organization for Research } \\
\text { and Treatment of Cancer Quality of Life Questionnaire Core 30, EORTC-QLQ-PAN26 = European Organization for Research and Treatment of Cancer Quality of Life Questionnaire } \\
\text { for Pancreatic Cancer, CRT = Chemoradiation, OS = Overall survival, CES-D = Center for Epidemiologic Studies Depression Scale, FACT-Hep = Functional Assessment of Cancer } \\
\text { Therapy-Hepatobiliary Cancer, GI = Gastrointestinal, HIGRT = Hypofractionated image-guided radiation therapy, PRO-CTCAE = Patient-Reported Outcomes version of the Common } \\
\text { Terminology Criteria for Adverse Events, SDS = Symptom Distress Scale, LASA = Linear Analog Self-Assessment, and RT = Radiation therapy. }\end{array}$} \\
\hline
\end{tabular}




\section{Conclusions}

The importance of assessing the patient's viewpoints through PROs is now recognized as critical data for patient care and trial design. Thus, increasing efforts are being dedicated toward incorporating PRO measures in clinical studies. The insights that these data provide can have profound effects on therapeutic decisions, since life expectancy with this disease remains dismal. Balancing QoL with therapeutic efficacy will likely have the most impact on patient satisfaction and clinical outcomes by personalizing care for each patient.

However, challenges remain in adopting the best practices into clinical trials, since there is no consensus with regards to the best PROM for a given study. Like any individual patient or treatment, the PROM must be tailored to data that would likely be relevant given the known morbidity of the cancer and its associated treatments. Among pancreatic cancer patients, data that can be generalized is of paramount importance, hence the underlying challenge of achieving a standard or benchmark that would allow clinicians and investigators to compare across studies and modalities. Such benchmarks might be the choice of measures, time points assessed, analyses, and interpretational techniques. In the absence of a unifying approach, the best practice for investigators and clinicians aiming to incorporate PRO data into their studies is to be aware of the characteristics of the PRO tools they are selecting and whether a combination might be necessary.

While this review focuses primarily on PROMs that can be used in patients with pancreatic cancer receiving radiotherapy, most of these measures can be used in other kinds of interventions in pancreatic cancer (e.g., chemotherapy or surgery) depending on the domains of interest. For trials involving radiotherapy in pancreatic cancer, the combination of a general QoL measure with a disease-specific PROM (e.g., EORTC-QLQ-PAN26) should be employed for a comprehensive understanding of the patient experience and symptomatology. The data generated offer insights into the patient's perspective and can help physicians offer tailored therapies with the patient's concerns in mind. More importantly, PROs might help bridge the relationship between the physician and patient, leading to better communication and insight, which, in turn, would lead to better outcomes and care satisfaction.

Author Contributions: Conceptualization: R.K., J.A.J., E.B.L., C.M.T.; Supervision: E.B.L., C.M.T.; Visualization: R.K., D.L., N.D.N., M.B.E.A.; Writing—original draft: R.K., J.A.J., D.L., N.D.N., M.B.E.A.; Writing—reviewing and editing: R.K., J.A.J., E.B.L., C.M.T. All authors have read and agreed to the published version of the manuscript.

Funding: This research received no external funding.

Conflicts of Interest: C.M.T. is supported by funding from the NIH under award R01CA227517-01A1, Cancer Prevention \& Research Institute of Texas (CPRIT) grant RR140012, V Foundation (V2015-22), the Kimmel Foundation, Sabin Family Foundation Fellowship, Reaumond Family Foundation, Childress Institute Funds, and the McNair Foundation.

\section{References}

1. Schnipper, L.E.; Davidson, N.E.; Wollins, D.S.; Blayney, D.W.; Dicker, A.P.; Ganz, P.A.; Hoverman, J.R.; Langdon, R.; Lyman, G.H.; Meropol, N.J.; et al. Updating the American Society of Clinical Oncology Value Framework: Revisions and Reflections in Response to Comments Received. J. Clin. Oncol. 2016, 34, 2925-2934. [CrossRef] [PubMed]

2. Cherny, N.I.; Sullivan, R.; Dafni, U.; Kerst, J.M.; Sobrero, A.; Zielinski, C.; de Vries, E.G.E.; Piccart, M.J. A standardised, generic, validated approach to stratify the magnitude of clinical benefit that can be anticipated from anti-cancer therapies: The European Society for Medical Oncology Magnitude of Clinical Benefit Scale (ESMO-MCBS). Ann. Oncol. 2015, 26, 1547-1573. [CrossRef]

3. Levit, L.A.; Balogh, E.P.; Nass, S.J.; Ganz, P.A. Committee on Improving the Quality of Cancer Care: Addressing the Challenges of an Aging Population; National Academies Press: Washington, DC, USA, 2013; p. 413.

4. Basch, E.; Deal, A.M.; Dueck, A.C.; Scher, H.I.; Kris, M.G.; Hudis, C.; Schrag, D. Overall Survival Results of a Trial Assessing Patient-Reported Outcomes for Symptom Monitoring During Routine Cancer Treatment. JAMA 2017, 318, 197-198. [CrossRef] 
5. Patrick, D.L.; Burke, L.B.; Powers, J.H.; Scott, J.A.; Rock, E.P.; Dawisha, S.; O'Neill, R.; Kennedy, D.L. Patient-Reported Outcomes to Support Medical Product Labeling Claims: FDA Perspective. Value Health 2007, 10, S125-S137. [CrossRef]

6. Kluetz, P.G.; Slagle, A.; Papadopoulos, E.J.; Johnson, L.L.; Donoghue, M.; Kwitkowski, V.E.; Chen, W.-H.; Sridhara, R.; Farrell, A.T.; Keegan, P.; et al. Focusing on Core Patient-Reported Outcomes in Cancer Clinical Trials: Symptomatic Adverse Events, Physical Function, and Disease-Related Symptoms. Clin. Cancer Res. 2016, 22, 1553-1558. [CrossRef] [PubMed]

7. Gotay, C.C.; Kawamoto, C.T.; Bottomley, A.; Efficace, F. The Prognostic Significance of Patient-Reported Outcomes in Cancer Clinical Trials. J. Clin. Oncol. 2008, 26, 1355-1363. [CrossRef] [PubMed]

8. Atkinson, T.M.; Ryan, S.J.; Bennett, A.V.; Stover, A.M.; Saracino, R.M.; Rogak, L.J.; Jewell, S.T.; Matsoukas, K.; $\mathrm{Li}, \mathrm{Y}$;; Basch, E. The association between clinician-based common terminology criteria for adverse events (CTCAE) and patient-reported outcomes (PRO): A systematic review. Support. Care Cancer 2016, 24, 3669-3676. [CrossRef] [PubMed]

9. Christodoulou, M.; McCloskey, P.; Stones, N.; Bayman, N.; Burt, P.; Chittalia, A.; Harris, M.; Lee, L.; Pemberton, L.; Sheikh, H.; et al. Investigation of a Patient Reported Outcome tool to assess radiotherapy-related toxicity prospectively in patients with lung cancer. Radiother. Oncol. 2014, 112, 244-249. [CrossRef]

10. Dueck, A.C.; Mendoza, T.R.; Mitchell, S.A.; Reeve, B.B.; Castro, K.M.; Rogak, L.J.; Atkinson, T.M.; Bennett, A.V.; Denicoff, A.M.; O'Mara, A.M.; et al. Validity and Reliability of the US National Cancer Institute's Patient-Reported Outcomes Version of the Common Terminology Criteria for Adverse Events (PRO-CTCAE). JAMA Oncol. 2015, 1, 1051-1059. [CrossRef]

11. Talib, T.L.; DeChant, P.; Kean, J.; Monahan, P.O.; Haggstrom, D.A.; Stout, M.E.; Kroenke, K. A qualitative study of patients' perceptions of the utility of patient-reported outcome measures of symptoms in primary care clinics. Qual. Life Res. 2018, 27, 3157-3166. [CrossRef]

12. Tong, H.; Fan, Z.; Liu, B.; Lu, T. The benefits of modified FOLFIRINOX for advanced pancreatic cancer and its induced adverse events: A systematic review and meta-analysis. Sci. Rep. 2018, 8, 1-8. [CrossRef] [PubMed]

13. De Vita, F.; Ventriglia, J.; Febbraro, A.; Laterza, M.M.; Fabozzi, A.; Savastano, B.; Petrillo, A.; Diana, A.; Giordano, G.; Troiani, T.; et al. NAB-paclitaxel and gemcitabine in metastatic pancreatic ductal adenocarcinoma (PDAC): From clinical trials to clinical practice. BMC Cancer 2016, 16, 709. [CrossRef] [PubMed]

14. Siegel, R.L.; Miller, K.D.; Jemal, A. Cancer statistics, 2019. CA Cancer J. Clin. 2019, 69, 7-34. [CrossRef] [PubMed]

15. Deng, Y.; Tu, H.; Pierzynski, J.A.; Miller, E.D.; Gu, X.; Huang, M.; Chang, D.W.; Ye, Y.; Hildebrandt, M.A.T.; Klein, A.P.; et al. Determinants and prognostic value of quality of life in patients with pancreatic ductal adenocarcinoma. Eur. J. Cancer 2018, 92, 20-32. [CrossRef]

16. Grant, S.R.; Noticewala, S.S.; Mainwaring, W.; Lin, T.A.; Miller, A.B.; Jethanandani, A.; Espinoza, A.F.; Gunn, G.B.; Fuller, C.D.; Thomas, C.R., Jr.; et al. Non-English language validation of patient-reported outcome measures in cancer clinical trials. Support. Care Cancer 2020, 28, 2503-2505. [CrossRef] [PubMed]

17. Holzner, B.; Bode, R.K.; Hahn, E.A.; Cella, D.; Kopp, M.; Sperner-Unterweger, B.; Kemmler, G. Equating EORTC QLQ-C30 and FACT-G scores and its use in oncological research. Eur. J. Cancer 2006, 42, 3169-3177. [CrossRef] [PubMed]

18. Herman, J.M.; Kitchen, H.; Degboe, A.; Aldhouse, N.V.J.; Trigg, A.; Hodgin, M.; Narang, A.; Johnson, C.D. Exploring the patient experience of locally advanced or metastatic pancreatic cancer to inform patient-reported outcomes assessment. Qual. Life Res. 2019, 28, 2929-2939. [CrossRef]

19. Mendoza, T.R.; Wang, X.S.; Cleeland, C.S.; Morrissey, M.; Johnson, B.A.; Wendt, J.K.; Huber, S.L. The rapid assessment of fatigue severity in cancer patients. Cancer 1999, 85, 1186-1196. [CrossRef]

20. Cleeland, C.S.; Karen, R. Pain assessment: Global use of the Brief Pain Inventory. Ann. Acad. Med. Singap. 1994, 23, 129-138.

21. Ganz, P.A.; Schag, C.A.C.; Lee, J.J.; Sim, M.-S. The CARES: A generic measure of health-related quality of life for patients with cancer. Qual. Life Res. 1992, 1, 19-29. [CrossRef]

22. National Comprehensive Cancer Network. Distress Management Clinical Practice Guidelines in Oncology. J. Natl. Compr. Cancer Netw. 2003, 1, 344. [CrossRef] 
23. Brueura, E.; Kuehn, N.; Miller, M. The Edmonton Symptom Assessment System (ESAS): A Simple Method for the Assessment of Palliative Care Patients. J. Palliait. Care 1991, 7, 6-9. [CrossRef]

24. Aaronson, N.K.; Ahmedzai, S.; Bergman, B.; Bullinger, M.; Cull, A.; Duez, N.J.; Filiberti, A.; Flechtner, H.; Fleishman, S.B.; de Haes, J.C.J.M.; et al. The European Organization for Research and Treatment of Cancer QLQ-C30: A Quality-of-Life Instrument for Use in International Clinical Trials in Oncology. J. Natl. Cancer Inst. 1993, 85, 365-376. [CrossRef]

25. Groenvold, M.; Petersen, M.A.; Aaronson, N.K.; Arraras, J.I.; Blazeby, J.M.; Bottomley, A.; Fayers, P.M.; de Graeff, A.; Hammerlid, E.; Kaasa, S.; et al. The development of the EORTC QLQ-C15-PAL: A shortened questionnaire for cancer patients in palliative care. Eur. J. Cancer 2006, 42, 55-64. [CrossRef] [PubMed]

26. Fitzsimmons, D.; Johnson, C.D.; George, S.; Payne, S.; Sandberg, A.A.; Bassi, C.; Beger, H.G.; Birk, D.; Grahm, A.L.; Jeekel, J.; et al. Development of a Disease Specific Quality of Life (QoL) Questionnaire Module to Supplement the EORTC Core Cancer QoL Questionnaire, the QLQ-C30 in Patients with Pancreatic Cancer. Eur. J. Cancer 1999, 35, 939-941. [CrossRef]

27. Herdman, M.; Gudex, C.; Lloyd, A.; Janssen, M.; Kind, P.; Parkin, D.; Bonsel, G.; Badia, X. Development and preliminary testing of the new five-level version of EQ-5D (EQ-5D-5L). Qual. Life Res. 2011, 20, 1727-1736. [CrossRef] [PubMed]

28. Cella, D.; Eton, D.T.; Lai, J.-S.; Peterman, A.H.; Merkel, D.E. Combining Anchor and Distribution-Based Methods to Derive Minimal Clinically Important Differences on the Functional Assessment of Cancer Therapy (FACT) Anemia and Fatigue Scales. J. Pain Symptom Manag. 2002, 24, 547-561. [CrossRef]

29. Heffernan, N.; Cella, D.; Webster, K.; Odom, L.; Martone, M.; Passik, S.; Bookbinder, M.; Fong, Y.; Jarnagin, W.; Blumgart, L. Measuring Health-Related Quality of Life in Patients With Hepatobiliary Cancers: The Functional Assessment of Cancer Therapy-Hepatobiliary Questionnaire. J. Clin. Oncol. 2002, 20, 2229-2239. [CrossRef]

30. Yount, S.; Cella, D.; Webster, K.; Heffernan, N.; Chang, C.-H.; Odom, L.; van Gool, R. Assessment of Patient-Reported Clinical Outcome in Pancreatic and Other Hepatobiliary Cancers: The FACT Hepatobiliary Symptom Index. J. Pain Symptom Manag. 2002, 24, 32-44. [CrossRef]

31. Butt, Z.; Parikh, N.D.; Beaumont, J.L.; Rosenbloom, S.K.; Syrjala, K.L.; Abernethy, A.P.; Benson, A.B.; Cella, D. Development and validation of a symptom index for advanced hepatobiliary and pancreatic cancers: The National Comprehensive Cancer Network Functional Assessment of Cancer Therapy (NCCN-FACT) Hepatobiliary-Pancreatic Symptom Index (NFHSI). Cancer 2012, 118, 5997-6004. [CrossRef]

32. Eypasch, E.; Williams, J.I.; Wood-Dauphinee, S.; Ure, B.M.; Schmulling, C.; Neugebauer, E.; Troidl, H. Gastrointestinal Quality of Life Index: Development, validation and application of a new instrument. Br. J. Surg. 1995, 82, 216-222. [CrossRef] [PubMed]

33. Cohen, S.R.; Mount, B.M.; Strobel, M.G.; Bui, F. The McGill Quality of Life Questionnaire: A measure of quality of life appropriate for people with advanced disease. A preliminary study of validity and acceptability. Palliat. Med. 1995, 9, 207-219. [CrossRef]

34. Cleeland, C.S.; Mendoza, T.R.; Wang, X.S.; Chou, C.; Harle, M.T.; Morrissey, M.; Engstrom, M.C. Assessing symptom distress in cancer patients: The M.D. Anderson symptom Inventory. Cancer 2000, 89, 1634-1646. [CrossRef]

35. Wang, X.S.; Williams, L.A.; Eng, C.; Mendoza, T.R.; Shah, N.A.; Kirkendoll, K.J.; Shah, P.K.; Trask, P.C.; Palos, G.R.; Cleeland, C.S. Validation and application of a module of the M. D. Anderson Symptom Inventory for measuring multiple symptoms in patients with gastrointestinal cancer (the MDASI-GI). Cancer 2010, 116, 2053-2063. [CrossRef] [PubMed]

36. Portenoy, R.K.; Thaler, H.T.; Kornblith, A.B.; McCarthy Lepore, J.; Friedlander-Klar, H.; Kiyasu, E.; Sobel, K.; Coyle, N.; Kemeny, N.; Norton, L.; et al. The Memorial Symptom Assessment Scale: An instrument for the evaluation of symptom prevalence, characteristics and distress. Eur. J. Cancer 1994, 30, 1326-1336. [CrossRef]

37. Heiberg, T.; Nordby, T.; Kvien, T.K.; Buanes, T. Development and preliminary validation of the pancreatic cancer disease impact score. Support. Care Cancer 2013, 21, 1677-1684. [CrossRef]

38. Bennett, A.V.; Dueck, A.C.; Mitchell, S.A.; Mendoza, T.R.; Reeve, B.B.; Atkinson, T.M.; Castro, K.M.; Denicoff, A.; Rogak, L.J.; Harness, J.K.; et al. Mode equivalence and acceptability of tablet computer-, interactive voice response system-, and paper-based administration of the U.S. National Cancer Institute's Patient-Reported Outcomes version of the Common Terminology Criteria for Adverse Events (PRO-CTCAE). Health Qual. Life Outcomes 2016, 14, 24. [CrossRef] 
39. Cella, D.; Riley, W.; Stone, A.; Rothrock, N.; Reeve, B.; Yount, S.; Amtmann, D.; Bode, R.; Buysse, D.; Choi, S.; et al. The Patient-Reported Outcomes Measurement Information System (PROMIS) developed and tested its first wave of adult self-reported health outcome item banks: 2005-2008. J. Clin. Epidemiol. 2010, 63, 1179-1194. [CrossRef]

40. Ware, J.E.; Sherbourne, C.D. The MOS 36-Item Short-Form Health Survey (SF-36): I. Conceptual Framework and Item Selection. Med. Care 1992, 30, 473-483. [CrossRef]

41. Ware, J.E.; Kosinski, M.; Keller, S.D. A 12-Item Short-Form Health Survey: Construction of Scales and Preliminary Tests of Reliability and Validity. Med. Care 1996, 34, 220-233. [CrossRef]

42. Bell, D.R.; Tannock, I.F.; Boyd, N.F. Quality of life measurement in breast cancer patients. Br. J. Cancer 1985, 51, 577-580. [CrossRef]

43. Guidance for industry: Patient-reported outcome measures: Use in medical product development to support labeling claims: Draft guidance. Health Qual. Life Outcomes 2006, 4, 79. [CrossRef] [PubMed]

44. Chuong, M.D.; Springett, G.M.; Freilich, J.M.; Park, C.K.; Weber, J.M.; Mellon, E.A.; Hodul, P.J.; Malafa, M.P.; Meredith, K.L.; Hoffe, S.E.; et al. Stereotactic Body Radiation Therapy for Locally Advanced and Borderline Resectable Pancreatic Cancer Is Effective and Well Tolerated. Int. J. Radiat. Oncol. Biol. Phys. 2013, 86, 516-522. [CrossRef] [PubMed]

45. Schellenberg, D.; Goodman, K.A.; Lee, F.; Chang, S.; Kuo, T.; Ford, J.M.; Fisher, G.A.; Quon, A.; Desser, T.S.; Norton, J.; et al. Gemcitabine Chemotherapy and Single-Fraction Stereotactic Body Radiotherapy for Locally Advanced Pancreatic Cancer. Int. J. Radiat. Oncol. Biol. Phys. 2008, 72, 678-686. [CrossRef] [PubMed]

46. Abi Jaoude, J.; Kouzy, R.; Nguyen, N.D.; Lin, D.; Noticewala, S.S.; Ludmir, E.B.; Taniguchi, C.M. Radiation therapy for patients with locally advanced pancreatic cancer: Evolving techniques and treatment strategies. Curr. Probl. Cancer 2020, 100607. [CrossRef] [PubMed]

47. Hoyer, M.; Roed, H.; Sengelov, L.; Traberg, A.; Ohlhuis, L.; Pedersen, J.; Nellemann, H.; Kiil Berthelsen, A.; Eberholst, F.; Engelholm, S.A.; et al. Phase-II study on stereotactic radiotherapy of locally advanced pancreatic carcinoma. Radiother. Oncol. 2005, 76, 48-53. [CrossRef]

48. Murphy, J.D.; Christman-Skieller, C.; Kim, J.; Dieterich, S.; Chang, D.T.; Koong, A.C. A Dosimetric Model of Duodenal Toxicity After Stereotactic Body Radiotherapy for Pancreatic Cancer. Int. J. Radiat. Oncol. Biol. Phys. 2010, 78, 1420-1426. [CrossRef]

49. Herman, J.M.; Chang, D.T.; Goodman, K.A.; Dholakia, A.S.; Raman, S.P.; Hacker-Prietz, A.; Iacobuzio-Donahue, C.A.; Griffith, M.E.; Pawlik, T.M.; Pai, J.S.; et al. Phase 2 Multi-institutional Trial Evaluating Gemcitabine and Stereotactic Body Radiotherapy for Patients With Locally Advanced Unresectable Pancreatic Adenocarcinoma. Cancer 2015, 121, 1128-1137. [CrossRef]

50. Polistina, F.; Costantin, G.; Casamassima, F.; Francescon, P.; Guglielmi, R.; Panizzoni, G.; Febbraro, A.; Ambrosino, G. Unresectable Locally Advanced Pancreatic Cancer: A Multimodal Treatment Using Neoadjuvant Chemoradiotherapy (Gemcitabine Plus Stereotactic Radiosurgery) and Subsequent Surgical Exploration. Ann. Surg. Oncol. 2010, 17, 2092-2101. [CrossRef]

51. Quan, K.; Sutera, P.; Xu, K.; Bernard, M.E.; Burton, S.A.; Wegner, R.E.; Zeh, H.; Bahary, N.; Stoller, R.; Heron, D.E. Results of a prospective phase 2 clinical trial of induction gemcitabine/capecitabine followed by stereotactic ablative radiation therapy in borderline resectable or locally advanced pancreatic adenocarcinoma. Pract. Radiat. Oncol. 2018, 8, 95-106. [CrossRef]

52. Krempien, R.; Muenter, M.; Huber, P.; Nill, S.; Friess, H.; Timke, C.; Didinger, B.; Buechler, P.; Heeger, S.; Herfarth, K.; et al. Randomized phase II-Study evaluating EGFR targeting therapy with Cetuximab in combination with radiotherapy and chemotherapy for patients with locally advanced pancreatic cancer-PARC: Study protocol [ISRCTN56652283]. BMC Cancer 2005, 5, 131. [CrossRef] [PubMed]

53. Morak, M.J.M.; Pek, C.J.; Kompanje, E.J.O.; Hop, W.C.J.; Kazemier, G.; van Eijck, C.H.J. Quality of life after adjuvant intra-arterial chemotherapy and radiotherapy versus surgery alone in resectable pancreatic and periampullary cancer: A prospective randomized controlled study. Cancer 2010, 116, 830-836. [CrossRef] [PubMed]

54. Knaebel, H.; Märten, A.; Schmidt, J.; Hoffmann, K.; Seiler, C.; Lindel, K.; Schmitz-Winnenthal, H.; Fritz, S.; Herrmann, T.; Goldschmidt, H.; et al. Phase III trial of postoperative cisplatin, interferon alpha-2b, and 5-FU combined with external radiation treatment versus 5-FU alone for patients with resected pancreatic adenocarcinoma-CapRI: Study protocol [ISRCTN62866759]. BMC Cancer 2005, 5, 37. [CrossRef] [PubMed] 
55. Serrano, P.E.; Herman, J.M.; Griffith, K.A.; Zalupski, M.M.; Kim, E.J.; Bekaii-Saab, T.S.; Ben-Josef, E.; Dawson, L.A.; Ringash, J.; Wei, A.C. Quality of Life in a Prospective, Multicenter Phase 2 Trial of Neoadjuvant Full-Dose Gemcitabine, Oxaliplatin, and Radiation in Patients With Resectable or Borderline Resectable Pancreatic Adenocarcinoma. Int. J. Radiat. Oncol. Biol. Phys. 2014, 90, 270-277. [CrossRef]

56. Short, M.; Goldstein, D.; Halkett, G.; Reece, W.; Borg, M.; Zissiadis, Y.; Kneebone, A.; Spry, N. Impact of Gemcitabine Chemotherapy and 3-Dimensional Conformal Radiation Therapy/5-Fluorouracil on Quality of Life of Patients Managed for Pancreatic Cancer. Int. J. Radiat. Oncol. Biol. Phys. 2013, 85, 157-162. [CrossRef]

57. Katz, M.H.G.; Ou, F.-S.; Herman, J.M.; Ahmad, S.A.; Wolpin, B.; Marsh, R.; Behr, S.; Shi, Q.; Chuong, M.; Schwartz, L.H.; et al. Alliance for clinical trials in oncology (ALLIANCE) trial A021501: Preoperative extended chemotherapy vs. chemotherapy plus hypofractionated radiation therapy for borderline resectable adenocarcinoma of the head of the pancreas. BMC Cancer 2017, 17, 505. [CrossRef]

58. Haddock, M.G.; Swaminathan, R.; Foster, N.R.; Hauge, M.D.; Martenson, J.A.; Camoriano, J.K.; Stella, P.J.; Tenglin, R.C.; Schaefer, P.L.; Moore, D.F.; et al. Gemcitabine, Cisplatin, and Radiotherapy for Patients With Locally Advanced Pancreatic Adenocarcinoma: Results of the North Central Cancer Treatment Group Phase II Study N9942. J. Clin. Oncol. 2007, 25, 2567-2572. [CrossRef]

59. Heras, P.; Kritikos, K.; Hatzopoulos, A.; Kritikos, N.; Karagiannis, S.; Mitsibounas, D. Effect of Combined Treatment Methods on Quality of Life in Patients With Pancreatic Cancer. Am. J. Ther. 2009, 16, 316-318. [CrossRef]

60. Hurt, C.N.; Mukherjee, S.; Bridgewater, J.; Falk, S.; Crosby, T.; McDonald, A.; Joseph, G.; Staffurth, J.; Abrams, R.A.; Blazeby, J.M.; et al. Health-Related Quality of Life in SCALOP, a Randomized Phase 2 Trial Comparing Chemoradiation Therapy Regimens in Locally Advanced Pancreatic Cancer. Int. J. Radiat. Oncol. Biol. Phys. 2015, 93, 810-818. [CrossRef]

61. Loehrer, P.J.; Feng, Y.; Cardenes, H.; Wagner, L.; Brell, J.M.; Cella, D.; Flynn, P.; Ramanathan, R.K.; Crane, C.H.; Alberts, S.R.; et al. Gemcitabine Alone Versus Gemcitabine Plus Radiotherapy in Patients With Locally Advanced Pancreatic Cancer: An Eastern Cooperative Oncology Group Trial. J. Clin. Oncol. 2011, 29, 4105-4112. [CrossRef]

62. Moore, M.A.S.; Goldstein, D.; Hamm, J.T.; Figer, A.; Hecht, J.R.; Gallinger, S.; Au, H.J.; Tasman, N.; Walde, D.; Wolff, R.A.; et al. Erlotinib plus gemcitabine compared with gemcitabine alone in patients with advanced pancreatic cancer: A phase III trial of the National Cancer Institute of Canada Clinical Trials Group. J. Clin. Oncol. Off. J. Am. Soc. Clin. Oncol. 2007, 25, 1960-1966. [CrossRef] [PubMed]

63. Neoptolemos, J.; Dunn, J.; Stocken, D.; Almond, J.; Link, K.; Beger, H.; Bassi, C.; Falconi, M.; Pederzoli, P.; Dervenis, C.; et al. Adjuvant chemoradiotherapy and chemotherapy in resectable pancreatic cancer: A randomised controlled trial. Lancet 2001, 358, 1576-1585. [CrossRef]

64. Neoptolemos, J.P.; Palmer, D.H.; Ghaneh, P.; Psarelli, E.E.; Valle, J.W.; Halloran, C.M.; Faluyi, O.; O’Reilly, D.A.; Cunningham, D.; Wadsley, J.; et al. Comparison of adjuvant gemcitabine and capecitabine with gemcitabine monotherapy in patients with resected pancreatic cancer (ESPAC-4): A multicentre, open-label, randomised, phase 3 trial. Lancet 2017, 389, 1011-1024. [CrossRef]

65. Oettle, H.; Post, S.; Neuhaus, P.; Gellert, K.; Langrehr, J.; Ridwelski, K.; Schramm, H.; Fahlke, J.; Zuelke, C.; Burkart, C.; et al. Adjuvant Chemotherapy With Gemcitabine vs Observation in Patients Undergoing Curative-Intent Resection of Pancreatic Cancer: A Randomized Controlled Trial. JAMA 2007, 297, 267-277. [CrossRef]

66. Conroy, T.; Hammel, P.; Hebbar, M.; Ben Abdelghani, M.; Wei, A.C.; Raoul, J.-L.; Choné, L.; Francois, E.; Artru, P.; Biagi, J.J.; et al. FOLFIRINOX or Gemcitabine as Adjuvant Therapy for Pancreatic Cancer. N. Engl. J. Med. 2018, 379, 2395-2406. [CrossRef]

(C) 2020 by the authors. Licensee MDPI, Basel, Switzerland. This article is an open access article distributed under the terms and conditions of the Creative Commons Attribution (CC BY) license (http://creativecommons.org/licenses/by/4.0/). 